\title{
ONLINE BOOK STORE MANAGEMENT
}

\section{AISWARYA \& MS. A. MANISHA}

Sixth Semester (IT) Student, Department of Information Technology, Sri Ramakrishna Institute of Technology, Coimbatore, India

\begin{abstract}
Now a day, in a busy schedule, we don't have time to go to the library. In our Digital India, all are processed through an online process. The online book store is nothing but purchasing a book online. Online book store allows a customer to purchase books through online, and select a book in a tabular form and add to cart, and we purchase the books through the online and online transaction (credit or debit card). Nowadays, it is very difficult to handle customer details. But in this software application, it is easy to maintain customer details. It maintains daily records, processing is very fast, stores customer information, and it is very useful to purchase books by sitting from home.

\section{KEYWORDS:}

Received: Mar 30, 2020; Accepted: Apr 19, 2020; Published: May 16, 2020; Paper Id.: IJISMRDJUN20201

\section{INTRODUCTION}

The online book store is used to purchase a book online rather than we go to the book shop. It saves more time. It has an application to develop the basic fundamental functions like customer details, book details and payments details. It stores more details about a customer and books. The purpose of this project is to create a web application and the user can purchase the books. This allows the customer to search the books based on the book title, book author name and book category.

After selecting the book, the book is displayed in a tabular format, it is add to cart, and we make payments through online transactions. All the information is given to the user (customers), and they know about this automation. The main objective of the "ONLINE BOOK STORE "is to manage the details about books, customers, payments (credit or debit card). It has more advantages like saves cost, saves time, fast purchasing, easy to handle customers records. It has some disadvantages like shipping charge, time delay, and return items.

It is very easy to buy books without any complexity. EX: customers need book means they have to go book store and select streams of books, buy the books, pay the bill and receive at the counter. There is more process and requires more time. But in our software web application, we complete all processes just with the minimum requirements of the time.

\section{LITERATURE REVIEW}

A) Barnes (2013) questioned, "Why online shopping is most popular". Many authors believe that the key reason is "convenience" (2013). The key reason is that a consumer favors the online store because online store satisfies the requirements. $86 \%$ of customers compare the online although not evident, and customers continue the shopping through online. The most preferred is the internet, avoiding long queues (2013). The time spent is in checking out, paying and waiting for deliverable and it takes consumes more time than queuing. So, some customers experience inconvenience with online 
The shipping cost is frustrating. It is eliminated using vouchers. In online shopping, identifying how the previous experience was, play a role. In case of positive outcome, consumers shop again; they experience the internet as successful shopping. The reasons for online shopping are

- Convenience

- $\quad$ Saving time $(53 \%)$

- $\quad$ No pressure from salesman $(55 \%)$

- Availability of vendor information (52\%)

\section{Some Analytics are as Follows}

Flipkart.com - It was founded in October 2007 by Binny Bansal and Bansal, who was alumni of Indian Institute of Technology (Delhi) worked for amazon. Acquired by Walmart, Flippant allows online transaction through credit or debit card and gift voucher and card swipe on delivery.

Amazon.com- It was founded by the garage of Bozos rented home in Washington. His parents spend 250000 for starts-up. July 1995, the company began services on online book store. In October 1997, the company announced itself as public. Amazon allows customers for online transactions, swipe on delivery.

Snap Deals- It is an Indian e-commerce company based in New Delhi, India, started by Knaul Bahl and Rohit Bansal in February 2010. Snap deals had 3.00.000 sellers in 2014, over 3 crore products across $800+$ categories.

From over 125,000 regional, National, international brands to reach the 4.000 towns and cities across the country.

The e-commerce site should have the following factors for consumer's usability

- Different parts of site after adding the item to shipping cart and return.

- Simple navigation from the home page to information and order links for specific products.

- Obvious shopping links or buttons.

- The consistent layout of the product information.

- Effective categorical organization of products.

- $\quad$ Selecting and scanning is easy on a list

\section{Feedback}

The feedback is another important component in the design of an e-commerce site. According to Norman, feedback sending back to the user information about what action has actually done, what result has accomplished is a known concept in the science of control and information theory. Imagine, trying to talk to someone when you cannot even hear your voice, or trying to sketch a picture with a pencil that leaves no mark there would be much feedback. Website feedback often consists of change verbal (or visual) information presented to the user. A simple example is using the sound of a cash register to confirm that a product has been added to a shopping cart. Ex: Include highlighting a selection made by the user or filling a field on a form based on a user's selection from a pull down list. Completed orders should be acknowledged fast. This process may be done with an acknowledgment or fulfillment page. The amount of time it takes to produce and download the page, it 
is a source of regression for Many E-commerce users. The empty page of our service, take a long time to receive products, may be interpreted as there must be something wrong with their order. If generating an acknowledgment may take longer time than what may be somewhat expected by the users, then the design should contain intermediate feedback to the user, indicating the progress being made toward acknowledgment or users fulfillment. Feedback should not draw user's attention away from important tasks of gathering information, selecting products, placing orders and payments. Eventually, feedback should not distract the user.

\section{CONCLUSIONS}

Nowadays, "Online Book Store "is very efficient and very useful and has many advantages. In these recent days, we are in busy schedules. We don't have enough time to go to Book store, select the categories of books, and search the books, paying the bill. Nowadays, this process is completed by less than ten minutes using the online store. Online Book Store allows customers to purchase books. The selected Books are in a tabular format and added to shipping cart and bought through net banking (online \& online Transaction) or home delivery, depending on the user's requirements. Customers can easily search the books based on the book title, book author name, book category, book edition etc. The major disadvantages are Time delay, some items are returned, more shipping charge, some warranty issues. Some customers feel that some items are better to buy at real store. The objective is managing the clear details about product bill, payments, orders, book stocks, and user's account.

\section{REFERENCES}

1. Bako's, J. Y. (1997). Reducing buyer search costs: Implications for electronic marketplaces. Management Science 43(12) 16131630 .

2. Car Baugh R \&Ghosh, K. (2005). Are college textbooks priced fairly? Challenge, 48 (5), 95-112. 2) Carlson, S. (2005). Online textbooks fail to

3. Make the grade, Chronicle of Higher Education, 51(23), A35-A36. Chevalier, J., \& 3) Goolsbee, A. (2003). Measuring prices and price competition online:Amazon.com and BarnesandNoble.com. Quantitative Marketing and Economics, 203-222.

4. Abdul Rehman Baloch \& Ali Bux Baloch, "Novel Inventory Control System for Purchase \& Store Section in Pakistani HEIs", Journal of Business Management and Research (JBMR), Vol. 5, Issue 1, pp. 27-32

5. Faisal Mustafa, "Collection Development in Libraries in Internet Era", International Journal of Library Science and Research (IJLSR), Vol. 5, Issue 2, pp. 45-50

6. S. Nazimsha \& M. Rajeswari, “Comparing Digital Marketing With Traditional Marketing and Consumer Preference Over Which Medium by Taking Concept of Ads", International Journal of Sales \& Marketing Management (IJSMM), Vol. 7, Issue 1, pp. 112

7. Swati Vijay, "A Study of Impact on Employment in Organised and Unorganised Retail Sector with Special Reference to Maharashtra State”, International Journal of Human Resources Management (IJHRM), Vol. 4, Issue 2, pp. 1-10 

